\title{
Cultural adaptation of health interventions including a nutrition component in Indigenous peoples: a systematic scoping review
}

Lisa Vincze $e^{1,2^{*}}$ D, Katelyn Barnes ${ }^{1,3}$, Mari Somerville ${ }^{1,2}$, Robyn Littlewood ${ }^{1,4}$, Heidi Atkins ${ }^{5}$, Ayala Rogany ${ }^{6}$ and Lauren T. Williams ${ }^{1,2}$

\begin{abstract}
Background: Indigenous populations throughout the world experience poorer health outcomes than nonindigenous people. The reasons for the health disparities are complex and due in part to historical treatment of Indigenous groups through colonisation. Evidence-based interventions aimed at improving health in this population need to be culturally safe. However, the extent to which cultural adaptation strategies are incorporated into the design and implementation of nutrition interventions designed for Indigenous peoples is unknown. The aim of this scoping review was to explore the cultural adaptation strategies used in the delivery of nutrition interventions for Indigenous populations worldwide.
\end{abstract}

Methods: Five health and medical databases were searched to January 2020. Interventions that included a nutrition component aimed at improving health outcomes among Indigenous populations that described strategies to enhance cultural relevance were included. The level of each cultural adaptation was categorised as evidential, visual, linguistic, constituent involving and/or socio-cultural with further classification related to cultural sensitivity (surface or deep).

Results: Of the 1745 unique records screened, 98 articles describing 66 unique interventions met the inclusion criteria, and were included in the synthesis. The majority of articles reported on interventions conducted in the USA, Canada and Australia, were conducted in the previous 10 years $(n=36)$ and focused on type 2 diabetes prevention ( $n=19)$ or management $(n=7)$. Of the 66 interventions, the majority included more than one strategy to culturally tailor the intervention, combining surface and deep level adaptation approaches $(n=51)$, however, less than half involved Indigenous constituents at a deep level $(n=31)$. Visual adaptation strategies were the most commonly reported $(n=57)$.

(Continued on next page)

\footnotetext{
* Correspondence: I.vincze@griffith.edu.au

'School of Health Sciences and Social Work, Griffith University, Parklands Drive, Gold Coast, Queensland 4222, Australia

${ }^{2}$ Menzies Health Institute Queensland, Griffith Health Centre, G40_8.86, Gold Coast, Queensland 4222, Australia

Full list of author information is available at the end of the article
}

(c) The Author(s). 2021 Open Access This article is licensed under a Creative Commons Attribution 4.0 International License, which permits use, sharing, adaptation, distribution and reproduction in any medium or format, as long as you give appropriate credit to the original author(s) and the source, provide a link to the Creative Commons licence, and indicate if changes were made. The images or other third party material in this article are included in the article's Creative Commons licence, unless indicated otherwise in a credit line to the material. If material is not included in the article's Creative Commons licence and your intended use is not permitted by statutory regulation or exceeds the permitted use, you will need to obtain permission directly from the copyright holder. To view a copy of this licence, visit http://creativecommons.org/licenses/by/4.0/. The Creative Commons Public Domain Dedication waiver (http://creativecommons.org/publicdomain/zero/1.0/) applies to the data made available in this article, unless otherwise stated in a credit line to the data. 


\begin{abstract}
(Continued from previous page)
Conclusion: This paper is the first to characterise cultural adaptation strategies used in health interventions with a nutrition component for Indigenous peoples. While the majority used multiple cultural adaptation strategies, few focused on involving Indigenous constituents at a deep level. Future research should evaluate the effectiveness of cultural adaptation strategies for specific health outcomes. This could be used to inform co-design planning and implementation, ensuring more culturally appropriate methods are employed.
\end{abstract}

Keywords: Aboriginal, Adult, Child, Co-design, Cultural safety, Community, Indigenous, First nations

\section{Background}

Indigenous peoples are recognised as being connected to a particular geographical region and having ancestral ties to the original land inhabitants prior to the development of modern states and borders [1, 2]. Indigenous peoples share unique cultural, societal, environmental, political and economic values that differ from the dominant society in which they live $[1,3]$. Despite having strong ancestral connections to original land owners, Indigenous peoples have consistently faced marginalization and the denial of basic human rights and represent about one third of the world's poorest communities [4]. The consequences of marginalisation and poverty include significantly poorer health outcomes [5] and reduced access to quality education and health services $[2,4,6]$. Persistent institutional racism further contributes to the health gap between Indigenous and non-indigneous people [7]. Clearly, action is required to address the health disparities faced by Indigenous peoples.

Improving diet quality has been shown to reduce the incidence of chronic diseases by up to $50 \%$ [8]. Therefore, effective nutrition interventions for combatting the gaps in health outcomes, particularly preventable chronic diseases, are needed for Indigenous peoples. While there is some evidence that nutrition interventions can improve diet-related health outcomes in Indigenous populations [9], a systematic review of 26 nutrition-related interventions among Australian Aboriginal and Torres Strait Islander people showed these gains to be short-term [10]. The authors concluded that lack of cultural adaptation limited the long-term effectiveness of interventions.

Indigenous peoples hold an holistic view of health incorporating community, environment, spiritual, emotional and physical wellbeing $[11,12]$. This is in contrast to the typical western model of health care provision which is more individualistic and disease-centric [13]. A recent systematic scoping review of Indigenous primary healthcare service delivery models identified a preference for healthcare that was accessible, culturally appropriate, holistic and involved community participation [14]. While all interventions need to be tailored, this is particularly true for Indigenous peoples, acknowledging their unique cultural needs and healthcare preferences.
Ensuring cultural safety of evidence-based interventions to improve health is therefore an important approach $[15,16]$. Curtis and colleagues propose a comprehensive definition for cultural safety that references the need for "healthcare organisations to influence healthcare to reduce bias and achieve equity" [17]. Cultural adaptation of an intervention involves careful consideration of the needs of the group for whom the intervention is being developed, as well as a meaningful collaboration during intervention design, development, implementation and evaluation $[15,18]$. Frameworks to achieve cultural adaptation have been developed. Kreuter and colleagues [19] describe five categories of adaptation commonly used to make health interventions more culturally appropriate (evidential, visual, linguistic, constituent involving, and socio-cultural). Resincow et al. [20] further posits that cultural sensitivity in developing interventions consists of two dimensions: surface (gives the sense of culturally appropriate messages reflecting settings and experiences of the group, including: music, pictures, foods, clothing, locations, and people) or deep (involves cultural sensitivity and a comprehensive understanding of the ethnic group's core cultural values, norms, and stressors affecting health behaviours).

The type and level of cultural adaptation strategies incorporated into the design and implementation of nutrition interventions for Indigenous peoples is unknown. According to Munn and colleagues [21], a scoping review is the type of review indicated when the aim is to identify key characteristics from an evidence base. This review therefore aims to examine the range of research undertaken on nutrition-related health interventions that are culturally adapted for Indigenous peoples focusing on the type and nature of adaptations made.

\section{Methods}

A scoping review was conducted systematically using a predefined protocol following the methodological framework of Arksey and O'Malley [22]. This approach included identifying the research question, selecting studies relevant to the research question, and charting the data - which includes summarising and reporting the results. This review was conducted in accordance with 
the Preferred Reporting Items for Systematic ReviewsScoping reviews extension checklist [23].

\section{Identifying the research question}

This review aimed to identify and categorise the key characteristics of cultural tailoring in health interventions with a nutrition component designed for Indigenous populations. The system outlined by the United Nations was adopted to determine Indigenous populations from any nation worldwide [24], noting that terms vary by country and geographical region and that the right to identify as Indigenous is the right of the people themselves [25]. Interventions conducted in mixed populations (i.e. Indigenous and non-indigenous peoples) were excluded.

Lifestyle interventions with a nutrition component with the aim of improving health outcomes, that described deliberate strategies used to enhance cultural relevance were included. Nutrition components of interventions were defined as the manipulation of food or dietary intake directly (e.g. provision of food or nutritional supplement) or indirectly (e.g. nutrition education). The nutrition component could be the sole focus of the intervention or delivered in conjunction with other components such as physical activity.

The typology of Kreuter and colleagues [19] was used to categorise the cultural adaptation strategies (Table 1). Articles were included if they described at least one of the five strategies. To further explore the extent of cultural adaptations, the model for understanding cultural sensitivities of Resincow and colleagues was also applied to included studies [20]. Each strategy was classed as 'surface' or 'deep' according to this model [20] (Table 1).

Published peer-reviewed studies, of any design, were considered for inclusion. Articles were included if the health outcomes were reported or if the health outcomes were specified but not yet evaluated within the existing publication. Where health outcomes were not stated, a category of 'no outcomes reported' was used. The health outcomes of interest were reported in the description of each included study (Additional file 1). Where health outcome data was available, the specific changes were extracted (e.g. decreased weight, increased intake of vegetable serves).

\section{Selection of studies relevant to the research question}

A structured search of available peer-reviewed literature was conducted with support from an experienced health librarian. The following databases were searched from inception to January, 2020: Embase, Cumulative Index to Nursing and Allied Health Literature (CINAHL), Cochrane Central Register Medline, PsychInfo, and Scopus (restricted to non-Medline indexed articles). Terms searched can be seen in Additional file 2. A web application (Rayaan) was used to manage the review (Available at: https://rayyan.ai/) [26]. All included studies were hand searched for references not captured by the initial search strategy. Reference lists of identified systematic reviews were searched to check all relevant papers from those reviews were included. Title/abstract and full-text screening were coded independently in duplicate. Discrepancies were resolved through discussion.

Table 1 Description of cultural adaptation strategies used to tailor nutrition health interventions for Indigenous peoples

\begin{tabular}{|c|c|c|}
\hline Strategy type & Strategy Description $^{a}$ & Sensitivity Level ${ }^{b}$ \\
\hline Peripheral & $\begin{array}{l}\text { Use of colours, imagery, fonts, pictures of the community, music, or declarative titles. } \\
\text { Gives the appearance of cultural appropriateness by packaging them in ways likely to appeal to a } \\
\text { group. These elements can create interest, establish credibility and set the tone for content in } \\
\text { printed communications }\end{array}$ & Surface \\
\hline Evidential & $\begin{array}{l}\text { Use of data on a given health issue within the population/community. } \\
\text { To enhance the perceived relevance of a health issue for a given group by presenting evidence of } \\
\text { its impact on that group. Such statements seek to raise awareness, concern, and or perceived } \\
\text { personal vulnerability to a health issue by showing that it affects the given group. }\end{array}$ & Surface \\
\hline Linguistic & $\begin{array}{l}\text { Use of dominant or traditional language. } \\
\text { To make programs and materials more accessible. } \\
\text { Must consider translations - should be culturally relevant, not direct translations. }\end{array}$ & $\begin{array}{l}\text { Surface (direct translation) } \\
\text { Deep (full translations with } \\
\text { culturally relevant } \\
\text { statements) }\end{array}$ \\
\hline $\begin{array}{l}\text { Constituent } \\
\text { Involving }\end{array}$ & $\begin{array}{l}\text { Drawing directly on the experience of members of the community. } \\
\text { Can range from using stories of community members, through to formal community guidance, } \\
\text { through to full ownership and directing of the project by the community. }\end{array}$ & $\begin{array}{l}\text { Surface (testimonials or } \\
\text { stories) } \\
\text { Deep (delivery of } \\
\text { intervention by community } \\
\text { members) }\end{array}$ \\
\hline $\begin{array}{l}\text { Sociocultural } \\
\text { strategies }\end{array}$ & $\begin{array}{l}\text { Discusses health issues in the context of broader social and cultural values and } \\
\text { characteristics. } \\
\text { The cultural values, beliefs and behaviours of the group are recognised, reinforced and built upon to } \\
\text { provide context and meaning to the health promotion activity. }\end{array}$ & Deep \\
\hline
\end{tabular}




\section{Charting of data}

Data from all included articles were extracted into a purposefully-developed spreadsheet by one researcher. A second researcher reviewed the coding on a subsample of articles $(n=24 ; \sim 25 \%)$ to ensure adequate and consistent application of the inclusion and exclusion criteria. Extracted data included: first author name and year of publication, intervention or program name, Indigenous population name (cited as reported in the article including any tribal affiliations) and location (including country), population of interest, level of intervention (individual (aimed at individual behaviour change), community (aimed at community behavioural or value change), or systems (aimed at environmental change (e.g. food systems)), a brief description of the intervention (including length, frequency and duration), theories of behaviour change used to underpin the intervention, a brief description of intervention outcomes (if reported), and whether or not formative research was undertaken in the same population or community (i.e. evidence for the intervention to improve health outcomes for the people involved). To achieve a yes for formative research, authors needed to refer to evidence (published or unpublished) to support the application of the intervention or program within the Indigenous population or specific community they were planning to work with. Involvement of the community in intervention design was extracted as 'yes-minimal' if community members were reported to have been consulted or asked to provide feedback, 'yes-maximal' if communitybased participatory research was employed, and 'no' if there was no community involvement in design of the intervention or program. Categories of strategies used to culturally tailor the intervention were extracted as per Table 1 [19].

Where multiple articles clearly reported on the same intervention and focussed on health outcomes, they were grouped for data extraction. As per the convention of scoping reviews, extracted data was summarised numerically to provide an overview of study characteristic frequency.

\section{Results}

The database search resulted in 3303 records with an additional 17 articles identified through other sources (Fig. 1). There were 1745 Articles remaining once

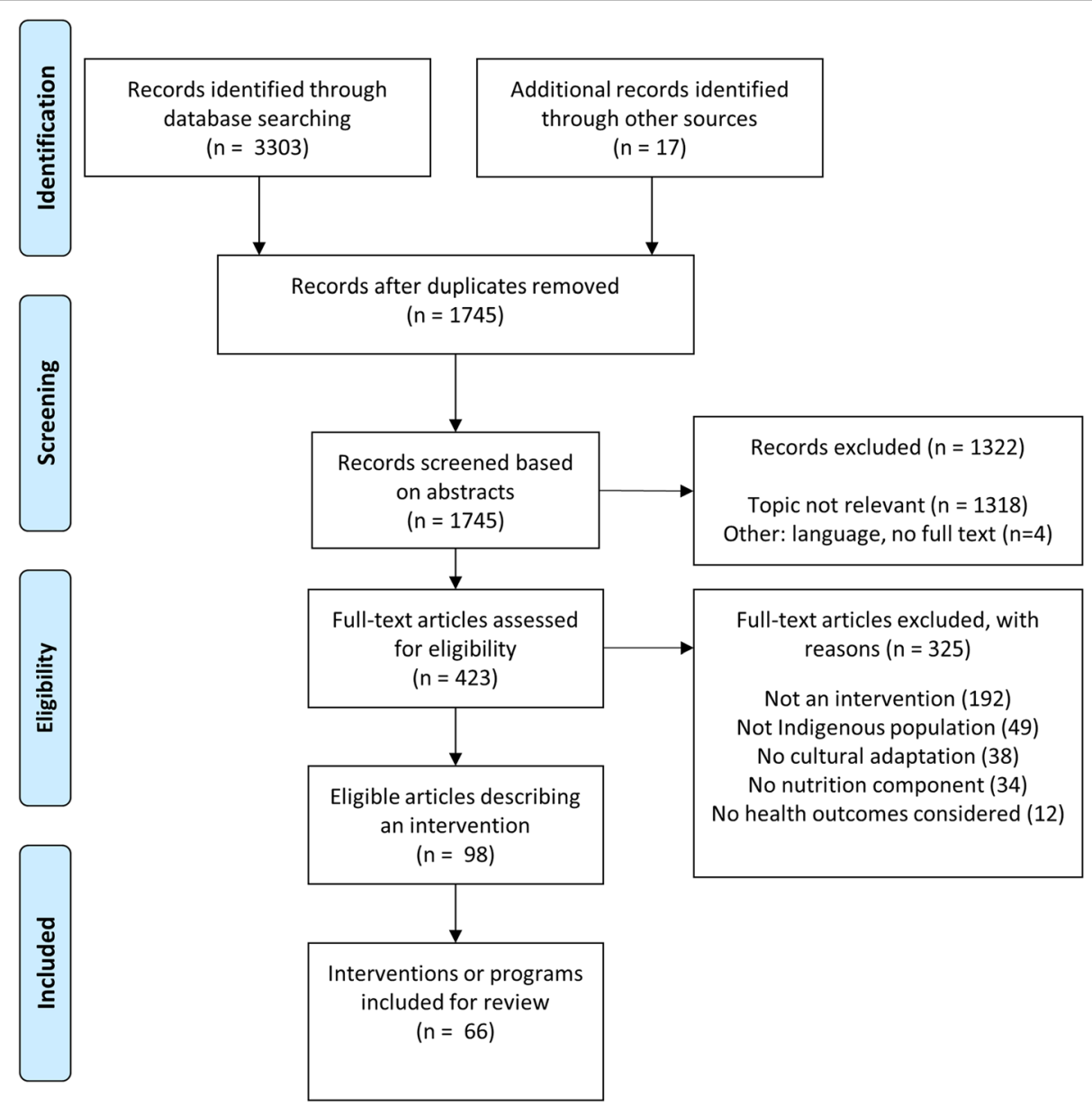

Fig. 1 Flow diagram for identification of culturally adapted health interventions for Indigenous peoples 
duplicates were removed. Of the 423 articles included in full text screening, 98 met the inclusion criteria. These 98 records described 66 unique interventions. The articles described 19 randomised controlled trials (RCTs), 3 Randomised Trials, 9 non-randomised trials and 35 prepost studies.

\section{Characteristics of included studies}

Table 2 summarises the characteristics of included interventions $(n=66)$ [27-92]. Individual study characteristics are described in Additional file 2. Where an intervention has multiple articles, the first publication by date has been used throughout as the source reference.

The majority of interventions were conducted in the USA among Native American $(\boldsymbol{n}=\mathbf{2 7})[28,32,33,37$, $38,42,43,46,48,50,52,56-58,61-63,65,70,72-74$, $82,83,87,89,92]$, Alaskan $(\boldsymbol{n}=4)[47,64,75,93]$ \& Hawaiian $(\boldsymbol{n}=\mathbf{2})[54,71]$ populations. Together with Australian Aboriginal and/or Torres Strait Islander $(\boldsymbol{n}=\mathbf{1 4})$ [27, 29-31, 40, 44, 51, 68, 78, 80, 85, 86, 88, 91] and Canadian First Nations People $(\boldsymbol{n}=\mathbf{1 1})[35,36,41,45$, $49,55,67,69,76,84,90]$ these three groups accounted for $85 \%$ of the literature included in this review. Figure 2 illustrates the interventions published by year and by Indigenous population and location.

Most interventions were designed for adults $(\boldsymbol{n}=29)$ $[27,28,36,39,40,42,46,51-54,58,60-63,66,71,74-$ $77,80,81,83,85-87,91]$, with less than a third $(\boldsymbol{n}=\mathbf{1 9})$ $[29-31,34,35,38,44,47,48,50,59,65,68,69,73,78$, $79,88,90]$ designed for both adults and children. Most interventions aimed to change health outcomes for diabetes prevention $(\boldsymbol{n}=19)[27,28,36,38,44,55,56,60$, $62,67,69,70,79,81,82,88,89,92,93]$, obesity prevention or treatment $(\boldsymbol{n}=\mathbf{1 1})[32,34,42,50,57,59,65,72$, $80,83,90]$, and diabetes management $(\boldsymbol{n}=7)[31,33,39$, $48,51,58,63,68,71,86,87,91]$. Figure 3 illustrates interventions published by Indigenous population and health focus.

\section{Intervention characteristics and cultural adaptation used in included studies}

Table 3 summarises the intervention characteristics and cultural adaptation strategies employed $(n=66)$. Interventions that incorporated both individual and community level approaches were the most common $(\boldsymbol{n}=32)[28,29,33,34,37,41,44,47,49,50,52-56$, $58-63,66-68,70,71,74-76,88,92,93]$. Two studies each employed community only [43, 90], system only $[35,57]$ and individual plus system $[39,91]$ level interventions. Seven interventions aimed to influence all three levels [30-32, 45, 69, 81, 89]. Most interventions $(\boldsymbol{n}=56)[28,30-39,41-50,52-59,61,63-69$, 77, 80, 81, 83-87, 90-92] cited formative research. Only one-third of interventions $(n=22)$ were informed by a combination of formative research at both the population and community level [31-33, 35, $37-39,42,44,46,49,54,64,66,69-74,86,90]$. Of the 46 studies that referred to formative research and also reported outcomes, most reported positive intervention outcomes $(\boldsymbol{n}=\mathbf{3 8} ; \mathbf{8 3 \%})[28,30-33,36-39$, $42,43,45,47,50,53,54,56-58,61,63,64,66-73$, $80,84-86,89-91,93]$. Nineteen interventions reported employing an underlying theory of behaviour change $[28,31-33,36,41,42,50,55,57,65,67,70$, $72,73,80,90,92,93]$. Of those that did, most employed multiple theories of behaviour change $(\boldsymbol{n}=$ 9) $[31,33,36,50,55,65,90,92,93]$ social cognitive theory $(\boldsymbol{n}=7)[28,41,42,57,72,73,80]$, or its predecessor of social learning theory $(\boldsymbol{n}=3)[32,67,70]$.

Almost all interventions employed more than one type of strategy to culturally tailor an intervention $(\boldsymbol{n}=\mathbf{6 5})$. Twelve interventions employed all five cultural adaptation strategies [34, 38, 48, 51, 53, 63-65, 68-70, 76], 22 employed four strategies [36, 39, 42, 44, 46, 47, 49, 54-61, 67, 72-74, 81], 23 employed three strategies [28-30, 32, $33,37,40,41,43,45,50,52,62,71,78,82,83,86-89,93]$, eight employed two strategies $[27,31,35,79,80,85,91$, 92], and only one study employed a single strategy [90]. Most interventions employed a combination of surface and deep cultural sensitivity approaches $(\boldsymbol{n}=\mathbf{5 1})$ [27-77], 12 used surface strategies only [78-89] and three studies [90-92] employed deep strategies only.

Cultural adaptation strategies used in each individual study are described in Additional file 3. Visual adaptation strategies were the most frequently used $(\boldsymbol{n}=57)$ such as ensuring print materials had pictures of Indigenous peoples, native foods, or colours of cultural significance $[28,29,32-34,36-49,51-76,78$, $79,81-89]$. The second most frequently used strategy was constituent involving $(\boldsymbol{n}=\mathbf{5 1})$ which ranged from the surface level strategies of requesting participant feedback, incorporation of participant stories or engagement of local media and businesses $(\boldsymbol{n}=20)$ [27, $33,36,39,42,44,46,47,61,63,68,78,80-84,86-$ 88 ], through to the deep level strategies of training of respected community members to deliver an intervention $(\boldsymbol{n}=31)[28-30,32,34,37,38,41,45,48-51$, $53,55-60,64,65,67,69,70,72,73,90-92]$. Sociocultural strategies were also widely employed $(\boldsymbol{n}=\mathbf{5 0})$ and included a range of activities such as incorporating traditional activities and ceremonies in the intervention, and ensuring childcare was available for participants [27-47, 49-66, 68-71, 73-76, 91, 92]. Linguistic strategies were employed in 41 of the interventions. Most of these were at the surface level [34, $40,42-44,48-50,52,54,57,59,62,63,68,70,75$, $79,81-84,86-89]$, such as incorporating single Indigenous words into intervention materials (e.g. name 
Table 2 Characteristics of the 66 included interventions

\begin{tabular}{|c|c|c|}
\hline Study Characteristic & $\mathrm{n}$ & (\%) \\
\hline \multicolumn{3}{|l|}{ Population (Country) } \\
\hline Native American / Native Alaskan / Native Hawaiian (USA) & 33 & 50.0 \\
\hline Aboriginal and/or Torres Strait Islander People (Australia) & 14 & 21.2 \\
\hline First Nations Peoples (Canada) & 11 & 16.8 \\
\hline Maori (New Zealand) & 4 & 6.0 \\
\hline Other Indigenous groups (inc. Palauan, Samoan, Fiji \& Soloman Islanders, Guatemalan) & 4 & 6.0 \\
\hline \multicolumn{3}{|l|}{ Year of Publication } \\
\hline$<1996$ & 3 & 4.5 \\
\hline $1996-2000$ & 8 & 12.1 \\
\hline $2001-2005$ & 6 & 9.1 \\
\hline $2006-2010$ & 13 & 19.7 \\
\hline $2011-2015$ & 20 & 30.3 \\
\hline $2016-2020$ & 16 & 24.3 \\
\hline \multicolumn{3}{|l|}{ Health Focus of Intervention } \\
\hline Diabetes prevention & 19 & 28.8 \\
\hline Obesity prevention and treatment & 12 & 18.2 \\
\hline Nutritional adequacy/Food security & 9 & 13.6 \\
\hline Women and infant health & 8 & 12.1 \\
\hline Diabetes management & 7 & 10.6 \\
\hline Cardiovascular disease prevention & 6 & 9.1 \\
\hline Chronic disease prevention (otherwise not already covered) & 5 & 7.6 \\
\hline \multicolumn{3}{|l|}{ Type of primary Nutrition Intervention component } \\
\hline Nutrition education & 34 & 51.6 \\
\hline Healthy food environment & 14 & 21.2 \\
\hline Individual dietary intervention & 8 & 12.1 \\
\hline Cooking classes & 4 & 6.0 \\
\hline Other (eg. Cultural stories, home-visits, dental care) & 6 & 9.1 \\
\hline \multicolumn{3}{|l|}{ Population } \\
\hline Adult & 29 & 43.9 \\
\hline Child & 18 & 27.3 \\
\hline Both & 19 & 28.8 \\
\hline \multicolumn{3}{|l|}{ Intervention duration } \\
\hline$<3$ months & 14 & 21.2 \\
\hline $3-6$ months & 15 & 22.7 \\
\hline$>6-12$ months & 15 & 22.7 \\
\hline$>12-24$ months & 11 & 16.7 \\
\hline$>24$ months & 10 & 15.2 \\
\hline Not reported & 1 & 1.5 \\
\hline
\end{tabular}

of the intervention), or by translating messages exactly from English into Indigenous languages. Deep linguistic strategies $(n=15)$ included providing all materials in Native languages and English, or by incorporating Native language and concepts into the intervention materials and activities $[38,39,51,53$,
60, 64-67, 69, 71, 72, 74, 76, 93]. Evidential strategies were least commonly employed $(\boldsymbol{n}=34)$ and included providing specific information about disease risk for Indigenous peoples in the community [30, 34-36, 38, $46-48,51,53-56,58,61,63-65,67-70,72-76,78$, $80,81,84,85,89]$. 


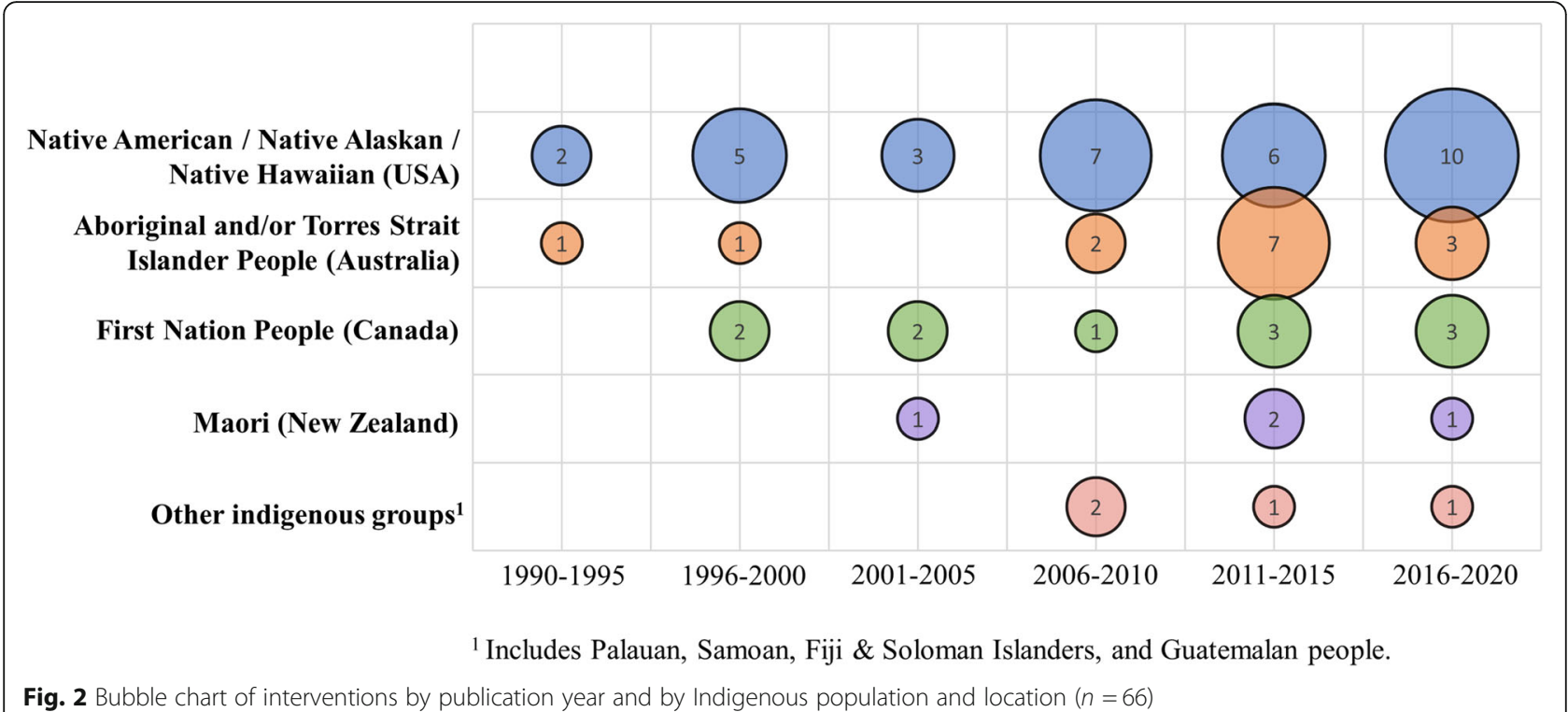

\section{Discussion}

This is the first scoping review, to our knowledge, to examine the extent and range of research undertaken to culturally adapt nutrition interventions for Indigenous peoples across the world. Despite there being no restriction on year of publication, the review found only $98 \mathrm{pa}-$ pers representing 66 studies that fit the inclusion criteria. The publication rate on this topic appears to be accelerating with more than half of the included studies $(n=36)$ published in the past decade. Most studies were conducted with first peoples in the USA, Australia and Canada, despite the fact that Indigenous peoples inhabit over 90 countries worldwide [94]. This may be partly due to the shared experience of European colonization in these countries, and subsequently the need to sensitively adapt health care to improve cultural appropriateness $[25,95$,
96]. Interventions included in this review had a strong emphasis on the prevention and management of diabetes and obesity. This is consistent with the known prevalence of metabolic disease which occurs at higher rates in Indigenous compared with non-indigenous populations [97-99], and important given these conditions are responsible for much of the gap in life expectancy and burden of disease between Indigenous and non-indigenous peoples [100]. It is important to note that the representation of research in low- and middle-income countries was clearly absent, as was a focus on the double burden of malnutrition experienced in many Indigenous peoples from these nations $[101,102]$. Further research in this area is urgently needed.

The review shows that there has been a concerted effort to culturally adapt the design and delivery of

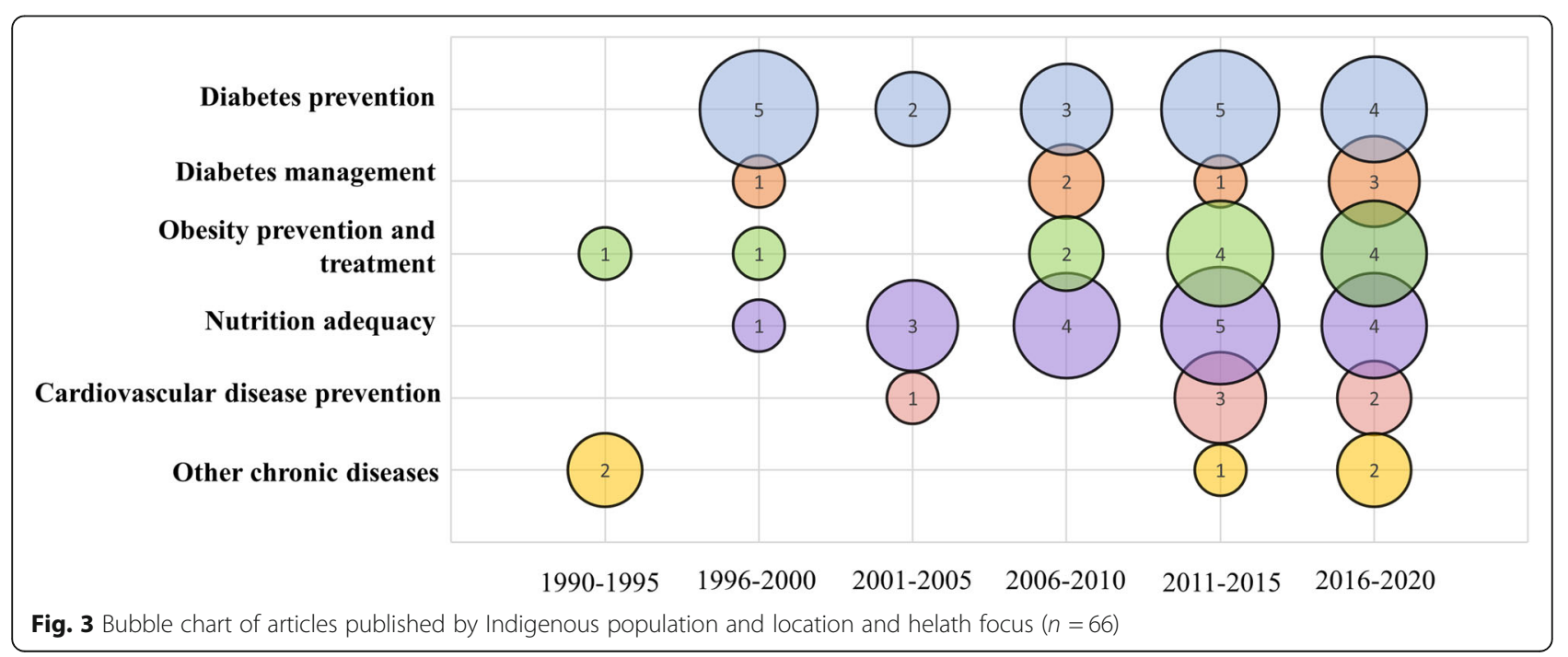


Table 3 Summary of Intervention chracteristics and cultural adaptation strategies $(n=66)$

\begin{tabular}{|c|c|c|}
\hline Study Characteristic & n (\%) & $(\%)$ \\
\hline \multicolumn{3}{|l|}{ Level of Intervention } \\
\hline Individual only & 12 & 18.2 \\
\hline Community only & 2 & 3.0 \\
\hline System only & 2 & 3.0 \\
\hline Individual + Community & 32 & 48.5 \\
\hline Individual + System & 2 & 3.0 \\
\hline Community + System & 9 & 13.6 \\
\hline Individual + Community + System & 7 & 10.6 \\
\hline \multicolumn{3}{|l|}{ Level of Community Input on design } \\
\hline None & 16 & 24.2 \\
\hline Minimal & 21 & 31.8 \\
\hline Maximal & 29 & 43.9 \\
\hline \multicolumn{3}{|l|}{ Formative research cited } \\
\hline Population level & 28 & 42.4 \\
\hline Community level & 6 & 9.1 \\
\hline Both & 22 & 33.3 \\
\hline None & 10 & 15.2 \\
\hline \multicolumn{3}{|c|}{ Intervention based on Behavior change theory } \\
\hline None reported & 47 & 71.2 \\
\hline Social cognitive theory & 7 & 10.6 \\
\hline Social learning theory & 3 & 4.5 \\
\hline Multiple therories & 9 & 13.6 \\
\hline \multicolumn{3}{|l|}{ Number of cultural strategies employed ${ }^{a}$} \\
\hline 1 strategy & 1 & 1.5 \\
\hline 2 strategies & 8 & 12.1 \\
\hline 3 strategies & 23 & 34.8 \\
\hline 4 strategies & 22 & 33.3 \\
\hline 5 strategies & 12 & 18.2 \\
\hline \multicolumn{3}{|l|}{ 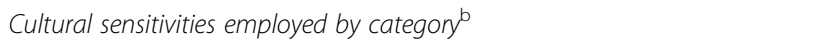 } \\
\hline Surface only & 12 & 19.7 \\
\hline Deep only & 3 & 3.0 \\
\hline Both surface and deep & 51 & 77.3 \\
\hline
\end{tabular}

nutrition interventions for Indigenous populations particularly in more contemporary research. The primary intervention strategy in over half of the studies was nutrition education, compared to less than one quarter of interventions aiming to improve the food environment. This tends to be consistent with nutrition interventions around the world despite the fact that nutrition knowledge, or lack of it, is usually not the underlying cause of health problems. This is particularly important to consider in Indigenous populations where social, economic and environmental inequalities pose significant challenges to health, rather than a lack of nutrition education [103, 104]. The United Nations Sustainable Development Goals [105] encompass aims relevant to improving Indigenous health including ending poverty and reducing inequalities. Interventions aiming to improve nutrition-related health in Indigenous populations need to incorporate strategies beyond nutrition education to address the social determinants of health at a community level $[105,106]$. Less than a third of the included studies reported basing their intervention on a stated behaviour change theory. This phase of intervention design needs to be considered given the findings of a systematic review of the use of behaviour change theories in nutrition interventions by Rigby and colleagues [107]. That review showed interventions based on behaviour change theories were more effective at achieving health outcomes [107]. The Rigby review also found social cognitive theory/social learning theory to be the most commonly applied theories in designing nutrition interventions, consistent with the findings in our review. This reinforces the dominance of nutrition education as a key component of interventions. The use of models that focus more on environmental change maybe more appropriate in designing interventions for indigenous populations.

While the majority of interventions were applied across multiple levels, this review found that only half of the interventions incorporated a community level approach. This is despite the definition of health for Indigenous peoples consistently adopting a holistic view incorporating social concepts that are expressed and applied in the community [94]. In a review of three environmental intervention case studies addressing chronic disease prevention interventions in American Indians, Gittelsohn and Rowan concluded that strategies were more successful when multiple intervention levels including environmental approaches with a particular emphasis placed on partnering with local stakeholders to positively influence healthy behaviours were implemented [108].

Importantly, this review identified that the majority of interventions employed multiple cultural adaptation strategies as classified according to Kreuter and colleagues' categories [19]. Most commonly this involved adopting peripheral and evidential strategies at a level that Resincow would classify as surface, which is consistent with interventions predominantly taking a nutrition education approach. Of interest was that deep linguistic approaches were least commonly utilised. A deep linguistic approach would involve making texts culturally relevant rather than simply a direct translation. Health education resources are often non-specific and lack cultural sensitivities for specific populations [109]. Further, direct language translations may lack cultural nuances putting cultural safety at risk. Health education 
resources need to be community-owned and incorporate cultural sensitivities to improve utiliastion and acceptance.

The majority of interventions involved key stakeholders at a surface level, and less than half involved constituents on a deep level. The review highlights that cultural adaptation of interventions to date has commonly involved engaging with Indigenous community stakeholders to elicit key understandings and experiences, for example, in conducting formative research. However, it was less common for interventions to be owned, delivered and/or directed by the community themselves. Similar findings to this review have also been reported in a recent scoping review evaluating community engagement in the design and implementation of chronic disease-based interventions for Indigenous populations [110]. In that review, Wali and colleagues reported that despite the agreed need to engage with Indigenous communities to support intervention engagement, few meaningfully consulted the community through all levels of intervention design and delivery [110]. Several authors have similarly argued that adopting participatory design approaches involving Indigenous communities as co-designers and decision-makers from the outset of intervention development is critical to achieve meaningful and lasting change [111-113].

A strength of this review was the application of an organisational system for categorising cultural adaption by a Kreuter and colleagues [19] which allowed for consistent and clear description of approaches currently used in nutrition interventions for Indigenous populations around the world. The additional application of Resnicow and colleagues [20] sensitivity levels to these categories has provided another analysis and categorisation of how interventions to date have been culturally adapted. This has highlighted areas for improvement in nutrition and health intervention research, particularly related to the need for deeper approaches that go beyond consultation, such as co-design. However, we note that while the classification systems by Kreuter and colleagues [19] and Resincow and colleagues [20] are published, they are by no means recognised as a combined validated tool to measure cultural adaptability. Constructing and validating a tool to guide cultural adaptation would be useful for the design of culturally safe interventions for Indigenous populations. Further, the classification schemes used are open to subjectivity in their interpretation and may therefore be influenced by the researcher during data extraction.

The review had other limitations. Given the significant differences between the cultures of Indigenous populations worldwide and the variety of health outcomes included, an evaluation of intervention effectiveness was not within the scope of this review. Determining intervention effectiveness by Indigenous population and health outcome is an important next step. Future evaluations of intervention effectiveness should consider the level of cultural adaptations made so as to better understand potential mechanisms for intervention success. Despite the rigourous search and screening methods, given the numerous terms used to describe Indigenous populations worldwide it is possible the search strategy was not able to capture all relevant studies. Further, Indigenous health research is often published in grey literature and subsequently may not have been identified for inclusion. While this review comprehensively investigated cultural adaptation strategies used, it did not evaluate the cultural safety of these interventions. Future research should consider the cultural safety of health interventions.

\section{Conclusion}

This review is an initial step in overcoming the many barriers to developing and implementing culturally safe interventions. The results of this review provide evidence of what has previously been done and highlights priority areas for further research. This scoping review found that there is growing literature reporting complex and diverse approaches to cultural adaptation of nutrition interventions for Indigenous populations across the world. Interventions commonly use a mix of approaches for cultural adaptation, however few are adopting approaches that involve constituents at deeper levels where interventions can be owned, delivered and/or directed by the community themselves. The review highlights the need to move beyond traditional nutrition education techniques focused on behaviour change, to strengthen cultural adaptation approaches that involve Indigenous people at the community level as co-designers and decision makers in all phases of the intervention. Further research is now needed to explore the effectiveness of the types and levels of cultural adaptations used on various health outcomes to determine the most effective strategies for culturally safe nutrition interventions. This is especially relevant given the need to improve health equity for Indigenous populations and the increasing number of interventions being conducted in this population group.

\section{Abbreviations \\ CINAHL: Cumulative Index to Nursing and Allied Health Literature; RCTs: Randomized Controlled Trials; USA: United States of America}

\section{Supplementary Information}

The online version contains supplementary material available at https://doi. org/10.1186/s12939-021-01462-x.

Additional file 1. Detailed summary of intervention characteristics

Additional file 2. Search strategy terms with example MeSH subject headings used in Medline and Scopus databases 
Additional file 3. Detailed summary of cultural adaptation strategies, formative research and theories of behaviour change used

\section{Acknowledgements}

The authors thank Tailane Scapin for her support in editing the references and final manuscript.

\section{Authors' contributions}

$L V, K B$ and $L W$ conceptulaised the hypothesis and design of the study. $K B$ supported the bibliographic search. LV, KB, MS, AR, HA, RL and LW participated in the collection, analysis and interpretation of data from identified articles. LV, KB, MS \& LW have written the manuscript and all authors made important contributions to different drafts. All authors approve the final manuscript and its submission to this journal.

\section{Funding}

This scoping review was supported as part of a larger project by the Children's Hospital Foundation's Woolworths Nutrition-Related Health Services Research Grant. The funder had no role in the study design, analysis and interpretation of data; in the communication of these results; and in the decision to submit the article for publication.

\section{Availability of data and materials}

All available data is included in the publication

\section{Declarations}

\section{Ethics approval and consent to participate}

Not applicable.

\section{Consent for publication}

Not applicable.

\section{Competing interests}

The authors declare that they have no competing interests.

\section{Author details}

${ }^{1}$ School of Health Sciences and Social Work, Griffith University, Parklands Drive, Gold Coast, Queensland 4222, Australia. ${ }^{2}$ Menzies Health Institute Queensland, Griffith Health Centre, G40_8.86, Gold Coast, Queensland 4222, Australia. ${ }^{3}$ Academic Unit of General Practice, Medical School, College of Health \& Medicine, The Australian National University, Canberra, Australian Capital Territory 2601, Australia. ${ }^{4}$ Health \& Wellbeing Queensland, Queensland Government, Brisbane, Queensland, Australia. ${ }^{5}$ Queensland Child and Youth Clinical Network, Clinical Excellence Queensland, Queensland Government, Brisbane, Queensland, Australia. ${ }^{6}$ Queensland Children's Hospital, Children's Health Queensland Hospital and Health Service, Queensland Government, Brisbane, Queensland, Australia.

Received: 20 January 2021 Accepted: 29 April 2021

Published online: 22 May 2021

\section{References}

1. United Nations. Indigenous peoples at the UN. 2021. Available from: https:// www.un.org/development/desa/indigenouspeoples/about-us.html. Accessed 20 Jan 2021.

2. United Nations. United Nations Department of Economic and Social Affairs: State of the world's indigenous peoples. In: Division for Senior Policy and Development. II ed. New York: United Nations; 2013. p. 200. https://www.un. org/esa/socdev/unpfii/documents/SOWIP/en/SOWIP_web.pdf.

3. World Health Organization. Indigenous populations. 2021. Available from: https://www.who.int/topics/health_services_indigenous/en/. Accessed 20 Jan 2021.

4. United Nations. Indigenous peoples and the MDGs. 2015. Available from: https://www.un.org/development/desa/indigenouspeoples/focus-areas/ post-2015-agenda/the-sustainable-development-goals-sdgs-and-indigenous/ mdgs.html. Accessed 20 Jan 2021.

5. Anderson I, Robson B, Connolly M, Al-Yaman F, Bjertness E, King A, et al. Indigenous and tribal peoples' health (the lancet-Lowitja Institute global collaboration): a population study. Lancet. 2016;388(10040):131-57. https:// doi.org/10.1016/S0140-6736(16)00345-7.

6. Mitrou F, Cooke M, Lawrence D, Povah D, Mobilia E, Guimond E, et al. Gaps in indigenous disadvantage not closing: a census cohort study of social determinants of health in Australia, Canada, and New Zealand from 19812006. BMC Public Health. 2014;14(1):201. https://doi.org/10.1186/1471-24 58-14-201.

7. Bourke CJ, Marrie $\mathrm{H}$, Marrie A. Transforming institutional racism at an Australian hospital. Aust Health Rev. 2019;43(6):611-8. https://doi.org/10.1 071/AH18062.

8. Willett WC, Koplan JP, Nugent R, Dusenbury C, Puska P, FGaziano TA. Prevention of chronic disease by means of diet and lifestyle changes. Disease control priorities in developing countries, vol. 2. New York: Oxford University Press; 2006.

9. Browne J, Lock M, Walker T, Egan M, Backholer K. Effects of food policy actions on indigenous peoples' nutrition-related outcomes: a systematic review. BMJ Glob Health. 2020;5(8):e002442. https://doi.org/10.1136/bmjgh-2 020-002442

10. Gwynn J, Sim K, Searle T, Senior A, Lee A, Brimblecombe J. Effect of nutrition interventions on diet-related and health outcomes of Aboriginal and Torres Strait islander Australians: a systematic review. BMJ Open. 2019;9(4):e025291. https://doi.org/10.1136/bmjopen-2018-02 5291.

11. Stephens C, Nettleton C, Porter J, Willis R, Clark S. Indigenous peoples' health--why are they behind everyone, everywhere? Lancet. 2005;366(9479): 10-3. https://doi.org/10.1016/S0140-6736(05)66801-8.

12. Mark GT, Lyons AC. Maori healers' views on wellbeing: the importance of mind, body, spirit, family and land. Soc Sci Med. 2010;70(11):1756-64. https://doi.org/10.1016/j.socscimed.2010.02.001.

13. Wade DT, Halligan PW. Do biomedical models of illness make for good healthcare systems? BMJ. 2004;329(7479):1398-401. https://doi.org/10.1136/ bmi.329.7479.1398.

14. Harfield SG, Davy C, McArthur A, Munn Z, Brown A, Brown N. Characteristics of indigenous primary health care service delivery models: a systematic scoping review. Glob Health. 2018;14(1):12. https://doi.org/10.1186/s12992018-0332-2.

15. Castro FG, Barrera M Jr, Holleran Steiker LK. Issues and challenges in the design of culturally adapted evidence-based interventions. Annu Rev Clin Psychol. 2010;6(1):213-39. https://doi.org/10.1146/annurev-clinpsy-0331 09-132032.

16. Movsisyan A, Arnold L, Evans R, Hallingberg B, Moore G, O'Cathain A, et al. Adapting evidence-informed complex population health interventions for new contexts: a systematic review of quidance. Implement Sci. 2019;14(1): 105. https://doi.org/10.1186/s13012-019-0956-5.

17. Curtis E, Jones R, Tipene-Leach D, Walker C, Loring B, Paine S-J, et al. Why cultural safety rather than cultural competency is required to achieve health equity: a literature review and recommended definition. Int J Equity Health. 2019;18(1):174. https://doi.org/10.1186/s12939-019-1082-3.

18. Marsiglia FF, Booth JM. Cultural adaptation of interventions in real practice settings. Res Soc Work Pract. 2015;25(4):423-32. https://doi.org/10.1177/104 9731514535989

19. Kreuter MW, Lukwago SN, Bucholtz RD, Clark EM, Sanders-Thompson V. Achieving cultural appropriateness in health promotion programs: targeted and tailored approaches. Health Educ Behav. 2003;30(2):133-46. https://doi. org/10.1177/1090198102251021.

20. Resnicow K, Baranowski T, Ahluwalia JS, Braithwaite RL. Cultural sensitivity in public health: defined and demystified. Ethn Dis. 1999;9(1):10-21.

21. Munn Z, Peters MDJ, Stern C, Tufanaru C, McArthur A, Aromataris E. Systematic review or scoping review? Guidance for authors when choosing between a systematic or scoping review approach. BMC Med Res Methodol. 2018;18(1):143. https://doi.org/10.1186/s12874-018-0611-x.

22. Arksey H, O'Malley L. Scoping studies: towards a methodological framework Int J Soc Res Methodol. 2005;8(1):19-32. https://doi.org/10.1080/1364557032 000119616.

23. Tricco AC, Lillie E, Zarin W, O'Brien KK, Colquhoun H, Levac D, et al. PRISMA extension for scoping reviews (PRISMA-SCR): checklist and explanation. Ann Intern Med. 2018;169(7):467-73. https://doi.org/10.7326/M18-0850.

24. United Nations. United Nations Permanent Forum on Indigenous Issues. Indigenous People Indigenous Voice Fact Sheet. 2008. Available from: https://www.un.org/esa/socdev/unpfii/documents/5session_factsheet1.pdf. Acessed 20 Jan 2021. 
25. United Nations. State of the World's indigenous peoples: implementing the United Nations declaration on the rights of indigenous peoples. New York: Department of Economic and Social Affairs; 2019. https://doi.org/10.18356/ 5cb401e7-en.

26. Ouzzani M, Hammady H, Fedorowicz Z, Elmagarmid A. Rayyan-a web and mobile app for systematic reviews. Syst Rev. 2016;5(1):210.

27. Abbott PA, Davison JE, Moore LF, Rubinstein R. Effective nutrition education for Aboriginal Australians: lessons from a diabetes cooking course. J Nutr Educ Behav. 2012;44(1):55-9. https://doi.org/10.1016/j. jneb.2010.10.006.

28. Allen P, Thompson JL, Herman CJ, Qualls C, Helitzer DL, Whyte AN, et al. Impact of periodic follow-up testing among urban American Indian women with impaired fasting glucose. Prev Chronic Dis. 2008;5(3):A76.

29. Balmer L, Foster V. Preliminary evaluation of the effects of a nutrition awareness project on the Ngaanyatjarra Pitjantjatjara Yankunytjatjara communities of Central Australia. Collegian. 1997;4(2):26-32. https://doi. org/10.1016/S1322-7696(08)60218-8.

30. Bertilone C, McEvoy S. Success in closing the gap: Favourable neonatal outcomes in a metropolitan aboriginal maternity group practice program. MJA. 2015;203(6):262.e1-7.

31. Brimblecombe J, Ferguson M, Liberato SC, Ball K, Moodie ML, Magnus A, et al. Stores healthy options project in remote indigenous communities (SHOP@RIC): a protocol of a randomised trial promoting healthy food and beverage purchases through price discounts and in-store nutrition education. BMC Public Health. 2013;13:744.

32. Caballero B, Davis S, Davis CE, Ethelbah B, Evans M, Lohman T, et al. Pathways: a school-based program for the primary prevention of obesity in American Indian children. J Nutr Biochem. 1998;9(9):535-43. https://doi. org/10.1016/S0955-2863(98)00049-7

33. Chambers RA, Rosenstock S, Neault N, Kenney A, Richards J, Begay K, et al. A home-visiting diabetes prevention and management program for American Indian youth. Diabetes Educ. 2015;41(6):729-47. https://doi.org/1 $0.1177 / 0145721715608953$.

34. Collier AF, Daiss S, Temengil E, Russell SC, Miller JC, Renguul FM. Developing an obesity intervention in Micronesia: from needs assessment to planning. Eval Program Plann. 2018;69:33-42. https://doi.org/10.1016/j.evalprogplan.2 018.04.003.

35. Counil É, Gauthier MJ, Blouin V, Grey M, Angiyou E, Kauki T, et al. Translational research to reduce trans-fat intakes in Northern Québec (Nunavik) Inuit communities: A success story? Int J Circumpolar Health. 2012;71(1):18833.

36. Daniel M, Green LW, Marion SA, Gamble D, Herbert CP, Hertzman C, et al. Effectiveness of community-directed diabetes prevention and control in a rural Aboriginal population in British Columbia, Canada. Soc Sci Med. 1999; 48(6):815-32. https://doi.org/10.1016/S0277-9536(98)00403-1.

37. Davis S, Gomez Y, Lambert L, Skipper B. Primary prevention of obesity in American Indian children. In: Williams CK, Kimm SYS, editors. Prevention and Treatment of Childhood Obesity. New York: New York Academy of Sciences; 1993. p. 167-80

38. DeBruyn L, Fullerton L, Satterfield D, Frank M. Integrating culture and history to promote health and help prevent type 2 diabetes in American Indian/ Alaska native communities: traditional foods have become a way to talk about health. Prev Chronic Dis. 2020;17:1-14.

39. DePue JD, Rosen RK, Seiden A, Bereolos N, Chima ML, Goldstein MG, et al. Implementation of a culturally tailored diabetes intervention with community health workers in American Samoa. Diabetes Educ. 2013;39(6): 761-71. https://doi.org/10.1177/0145721713504630.

40. Foley W, Spurr S, Lenoy L, De Jong M, Fichera R. Cooking skills are important competencies for promoting healthy eating in an urban indigenous health service. Nutr Diet. 2011;68(4):291-6. https://doi.org/ 0.1111/j.1747-0080.2011.01551.x

41. Gates A, Hanning RM, Gates M, Tsuji LJS. The food and nutrient intakes of first nations youth living in northern Ontario, Canada: evaluation of a harvest sharing program. J Hunger Environ Nutr. 2016;11(4):491-508. https:// doi.org/10.1080/19320248.2016.1157552.

42. Gittelsohn J, Kim EM, He S, Pardilla M. A food store-based environmental intervention is associated with reduced BMI and improved psychosocial factors and food-related behaviors on the Navajo nation. J Nutr. 2013;143(9): 1494-500. https://doi.org/10.3945/jn.112.165266.

43. Govula C, Kattelman K, Ren C. Culturally appropriate nutrition lessons increased fruit and vegetable consumption in American Indian children.
Top Clin Nutr. 2007;22(3):239-45. https://doi.org/10.1097/01.TIN.0000285378. 01218.67.

44. Gracey M, Bridge E, Martin D, Jones T, Spargo R, M. o, et al. An Aboriginaldriven program to prevent, control and manage nutrition-related "lifestyle" diseases including diabetes. Asia Pac J Clin Nutr. 2006;15(2):178-88.

45. Hanbazaza MA, Triador L, Ball GDC, Farmer A, Maximova KA, et al. The impact of school gardening on cree children's knowledge and attitudes toward vegetables and fruit. Can J Diet Pract Res. 2015;76(3):133-9. https:// doi.org/10.3148/cjdpr-2015-007.

46. Jernigan VBB, Williams M, Wetherill M, Taniguchi T, Jacob T, Cannady T, et al. Using community-based participatory research to develop healthy retail strategies in native American-owned convenience stores: the THRIVE study. Prev Med Rep. 2018;11:148-53. https://doi.org/10.1016/j.pmedr.2018. 06.012 .

47. Karanja N, Lutz T, Ritenbaugh C, Maupome G, Jones J, Becker T, et al. The TOTS community intervention to prevent overweight in American Indian toddlers beginning at birth: a feasibility and efficacy study. J Community Health. 2010;35(6):667-75. https://doi.org/10.1007/s10900-010-9270-5.

48. Kattelmann KK, Conti K, Ren C. The medicine wheel nutrition intervention: a diabetes education study with the Cheyenne River Sioux tribe. J Acad Nutr Diet. 2009;109(9):1532-9.

49. Kenny TA, MacLean J, Gale P, Keats S, Chan HM, Wesche SD. Linking health and the environment through education - a traditional food program in Inuvik, Western Canadian Arctic. J Hunger Environ Nutr. 2018;13(3):429-32. https://doi.org/10.1080/19320248.2017.1420330.

50. LaRowe TL, Wubben DP, Cronin KA, Vannatter SM, Adams A, K. r. Development of a culturally appropriate, home-based nutrition and physical activity curriculum for Wisconsin American Indian families. Prev Chronic Dis. 2007:4(4):A109-A.

51. Lee AJ, Bailey AP, Yarmirr D, O'Dea K, Mathews JD. Survival tucker: improved diet and health indicators in an Aboriginal community. Aust J Public Health. 1994;18(3):277-85. https://doi.org/10.1111/j.1753-6405.1994.tb00245.x.

52. Lee ET, Jobe JB, Yeh J, Ali T, Rhoades ER, Knehans AW, et al. A cardiovascular risk reduction program for American Indians with metabolic syndrome: the balance study. J Prim Prev. 2012;33(4):187-96. https://doi. org/10.1007/s10935-012-0273-0.

53. Leenen I, Givaudan M, Pick S, Venguer T, Vera J, Poortinga YH. Effectiveness of a Mexican health education program in a poverty-stricken rural area of Guatemala. J Cross-Cult Psychol. 2008;39(2):198-214. https://doi.org/10.1177/ 0022022107312588

54. Leslie JH. Uli'eo Koa program: incorporating a traditional Hawaiian dietary component. Pac Health Dialog. 2001;8(2):401-6.

55. Macaulay AC, Paradis G, Potvin L, Cross EJ, Saad-Haddad C, McComber A, et al. The Kahnawake schools diabetes prevention project: intervention, evaluation, and baseline results of a diabetes primary prevention program with a native community in Canada. Prev Med. 1997;26(6):779-90. https:// doi.org/10.1006/pmed.1997.0241.

56. Marlow E, Melkus GD, Bosma AM. Professional development. STOP diabetes! An educational model for native American adolescents in the prevention of diabetes. Diabetes Educ. 1998;24(4):441-8. https://doi.org/10.1177/0145721 79802400403.

57. Mattingly JA, Andresen PA. NAP SACC: Implementation of an obesity prevention intervention in an American Indian head start program. J Community Health Nurs. 2016;33(3):145-53. https://doi.org/10.1080/0737001 6.2016 .1191871 .

58. Mendenhall TJ, Berge JM, Harper P, GreenCrow B, LittleWalker N, WhiteEagle $\mathrm{S}$, et al. The family education diabetes series (FEDS): community-based participatory research with a midwestern American Indian community. Nurs Inq. 2010;17(4):359-72. https://doi.org/10.1111/j.1440-1800.2010.00508.x.

59. Mercer C, Riini D, Hamerton H, Morrison L, McPherson B. Evaluating a healthy eating, healthy action program in small Mãori communities in Aotearoa. N Z Aust J Prim Health. 2013;19(1):74-80. https://doi.org/10.1071/ PY11096.

60. Murphy E, McAuley KA, Bell D, McLay RT, Chisholm A, Hurley R, et al. A new approach to design and implement a lifestyle intervention programme to prevent type 2 diabetes in New Zealand Maori. Asia Pac J Clin Nutr. 2003; 12(4):419-22.

61. Murphy S, Wilson C. Breastfeeding promotion: a rational and achievable target for a type 2 diabetes prevention intervention in native American communities. J Hum Lact. 2008:24(2):193-8. https://doi.org/10.1177/ 0890334408317434 
62. Narayan KMV, Hoskin M, Kozak D, Kriska AM, Hanson RL, Pettitt DJ, et al. Randomized clinical trial of lifestyle interventions in Pima Indians: a pilot study. Diabet Med. 1998;15(1):66-72. https://doi.org/10.1002/(SICI)1096-913 6(199801)15:1<66::AID-DIA515>3.0.CO;2-A

63. Nelson RG, Pankratz VS, Ghahate DM, Bobelu J, Faber T, Shah VO. Homebased kidney care, patient activation, and risk factors for CKD progression in zuni indians a randomized, controlled clinical trial. CJASN. 2018;13(12):18019. https://doi.org/10.2215/CJN.06910618.

64. Nu J, Bersamin A. Collaborating with Alaska native communities to design a cultural food intervention to address nutrition transition. Prog Community Health Partnersh. 2017;11(1):71-80. https://doi.org/10.1353/cpr.2017.0009.

65. Redmond LC, Jock B, Gadhoke P, Chiu DT, Christiansen K, Pardilla M, et al. OPREVENT (obesity prevention and evaluation of InterVention effectiveness in NaTive north Americans): design of a multilevel, multicomponent obesity intervention for native American adults and households. Curr Dev Nutr. 2019;3(Suppl 2):81-93. https://doi.org/10.1093/cdn/nzz009.

66. Rolleston AK, Doughty R, Poppe K. Integration of kaupapa Māori concepts in health research: a way forward for Māori cardiovascular health? J Prim Health Care. 2016;8(1):60-6. https://doi.org/10.1071/HC15034.

67. Ronsley R, Lee AS, Kuzeljevic B, Panagiotopoulos C. Healthy buddies ${ }^{\mathrm{TM}}$ reduces body mass index $z$-score and waist circumference in Aboriginal children living in remote coastal communities. J Sch Health. 2013;83(9):60513. https://doi.org/10.1111/josh.12072.

68. Rowley KG, Daniel M, Skinner K, Skinner M, White GA, O'Dea K. Effectiveness of a community-directed 'healthy lifestyle' program in a remote Australian Aboriginal community. Aust N Z J Publ Health. 2000;24(2):136-44.

69. Saksvig Bl, Gittelsohn J, Harris SB, Hanley AJG, Valente TW, Zinman B. A pilot school-based healthy eating and physical activity intervention improves diet, food knowledge, and self-efficacy for native Canadian children. J Nutr. 2005;135(10):2392-8. https://doi.org/10.1093/jn/135.10.2392

70. Sauder KA, Dabelea D, Bailey-Callahan R, Kanott Lambert S, Powell J, James $\mathrm{R}$, et al. Targeting risk factors for type 2 diabetes in American Indian youth: the tribal turning point pilot study. Pediatr Obes. 2018;13(5):321-9. https:// doi.org/10.1111/ijpo.12223.

71. Shintani TT, Hughes CK, Beckham S, O'Connor HK. Obesity and cardiovascular risk intervention through the ad libitum feeding of traditional Hawaiian diet. Am J Clin Nutr. 1991;53(6 Suppl):1647s-51s.

72. Story M, Hannan PJ, Fulkerson JA, Rock BH, Smyth M, Arcan C, et al. Bright start: description and main outcomes from a group-randomized obesity prevention trial in American Indian children. Obesity. 2021; 20(11):2241-9.

73. Vastine A, Gittelsohn J, Ethelbah B, Anliker J, Caballero B. Formative research and stakeholder participation in intervention development. Am J Health Behav. 2005;29(1):57-69. https://doi.org/10.5993/AJHB.29.1.5.

74. Walters KL, LaMarr J, Levy RL, Pearson C, Maresca T, Mohammed SA, et al. Project həli?dx(w)/healthy hearts across generations: development and evaluation design of a tribally based cardiovascular disease prevention intervention for American Indian families. J Prim Prev. 2012;33(4):197-207. https://doi.org/10.1007/s10935-012-0274-z.

75. Witmer JM, Hensel MR, Holck PS, Ammerman AS, Will JC. Heart disease prevention for Alaska native women: a review of pilot study findings. J Women's Health. 2004;13(5):569-78. https://doi.org/10.1089/15409990412 80981.

76. Ziabakhsh S, Pederson A, Prodan-Bhalla N, Middagh D, Jinkerson-Brass S. Women-centered and culturally responsive heart health promotion among indigenous women in Canada. Health Promot Pract. 2016;17(6):814-26. https://doi.org/10.1177/1524839916633238.

77. Jiang L, Johnson A, Pratte K, Beals J, Bullock A, Manson SM. Long-term outcomes of lifestyle intervention to prevent diabetes in American Indian and Alaska native communities: the special diabetes program for Indians diabetes prevention program. Diabetes Care. 2018;41(7):1462-70. https://doi. org/10.2337/dc17-2685.

78. Blinkhorn F, Wallace J, Smith L, Blinkhorn AS. Developing leaflets to give dental health advice to Aboriginal families with young children. Int Dent J. 2014;64(4):195-9. https://doi.org/10.1111/idj.12108.

79. Brooking LA, Williams SM, Mann Jl. Effects of macronutrient composition of the diet on body fat in indigenous people at high risk of type 2 diabetes. Diabetes Res Clin Pract. 2012;96(1):40-6. https://doi.org/10.1016/j.diabres.2 011.11 .021$.

80. Canuto KJ, McDermott RA, Cargo M, Esterman AJ. Study protocol: a pragmatic randomised controlled trial of a 12-week physical activity and nutritional education program for overweight Aboriginal and Torres Strait Islander women. BMC Public Health. 2011;11:655.

81. Coppell KJ, Tipene-Leach DC, Pahau HLR, Williams SM, Abel S, lles M, et al. Two-year results from a community-wide diabetes prevention intervention in a high risk indigenous community: the Ngati and healthy project. Diabetes Res Clin Pract. 2009;85(2):220-7. https://doi.org/10.1016/j.diabres.2 009.05.009.

82. Gachupin FC, Joe JR. American Indian youth: a residential camp program for wellness. Health Dispar Res Pract. 2017;10(4):11.

83. Hemmingson K, Lucchesi R, Droke E, Kattelmann KK. Tailoring a web-based weight maintenance intervention for Northern Plains American Indian public university students. Health Educ J. 2016;75(5):528-39. https://doi. org/10.1177/0017896915607909.

84. Lawrence HP, Romanetz M, Rutherford L, Cappel L, Binguis D, Rogers JB. Effects of a community-based prenatal nutrition program on the oral health of Aboriginal preschool children in northern Ontario. Probe. 2004;38(4):17288.

85. Merrick J, Chong A, Parker E, Roberts-Thomson K, Misan G, Spencer J, et al. Reducing disease burden and health inequalities arising from chronic disease among indigenous children: an early childhood caries intervention. BMC Public Health. 2012;12(1):323. https://doi.org/10.1186/1471-24 58-12-323.

86. Quinn E, O'Hara BJ, Ahmed N, Winch S, McGill B, Banovic D, et al. Enhancing the get healthy information and coaching service for Aboriginal adults: evaluation of the process and impact of the program. Int J Equity Health. 2017;16(1):168-78. https://doi.org/10.1186/s12939-017-0641-8.

87. Robertson C, Kattelmann K, Ren C. Control of type 2 diabetes mellitus using interactive internet-based support on a Northern Plains Indian reservation: a pilot study. Top Clin Nutr. 2007;22(2):185-93. https://doi.org/10.1097/01.TIN. 0000270137.00099.91.

88. Seear KH, Atkinson DN, Lelievre MP, Henderson-Yates LM, Marley JV. Piloting a culturally appropriate, localised diabetes prevention program for young Aboriginal people in a remote town. Aust J Prim Health. 2019;25(5):495-500. https://doi.org/10.1071/PY19024

89. Teufel NI, Ritenbaugh CK. Development of a primary prevention program: insight gained in the Zuni diabetes prevention program. Clin Pediatr. 1998; 37(2):131-41. https://doi.org/10.1177/000992289803700211.

90. Anand SS, Davis AD, Ahmed R, Jacobs R, Xie C, Hill A, et al. A family-based intervention to promote healthy lifestyles in an Aboriginal community in Canada. Can J Public Health. 2007;98(6):447-52. https://doi.org/10.1007/ BF03405436.

91. Battersby MW, Kit JA, Prideaux C, Harvey PW, Collins JP, Mills PD. Implementing the flinders model of self-management support with Aboriginal people who have diabetes: findings from a pilot study. Aust J Prim Health. 2008;14(1):66-74. https://doi.org/10.1071/PY08009.

92. Brown B, Noonan C, Harris KJ, Parker M, Gaskill S, Ricci C, et al. Developing and piloting the journey to native youth health program in Northern Plains Indian communities. Diabetes Educ. 2013;39(1):109-18. https://doi.org/10.11 77/0145721712465343

93. Jiang L, Manson SM, Beals J, Henderson WG, Huang H, Acton KJ, et al. Translating the diabetes prevention program into American Indian and Alaska native communities: results from the special diabetes program for Indians diabetes prevention demonstration project. Diabetes Care. 2013. 36(7):2027-34. https://doi.org/10.2337/dc12-1250.

94. United Nations. Statistical division. State of the World's indigenous peoples. In: Department of Economic and Social Affairs. New York: United Nations Publications; 2009.

95. Paradies Y. Colonisation, racism and indigenous health. J Popul Res. 2016; 33(1):83-96. https://doi.org/10.1007/s12546-016-9159-y.

96. Pulver $\sqcup$, Haswell M, Ring I, Waldon J, Clark W, Whetung V, et al. Indigenous health: Australia, Canada, Aotearoa, New Zealand and the United States: laying claim to a future that embraces health for us all. Geneva: World Health Organization; 2010

97. Randall DA, Lujic S, Havard A, Eades SJ, Jorm L. Multimorbidity among Aboriginal people in New South Wales contributes significantly to their higher mortality. Med J Aust. 2018;209(1):19-23. https://doi.org/10.5694/ mja17.00878.

98. Schumacher C, Ferucci ED, Lanier AP, Slattery ML, Schraer CD, Raymer TW, et al. Metabolic syndrome: prevalence among American Indian and Alaska native people living in the southwestern United States and in Alaska. Metab Syndr Relat Disord. 2008;6(4):267-73. https://doi.org/10.1089/met.2008.0021. 
99. Hutchinson RN, Shin S. Systematic review of health disparities for cardiovascular diseases and associated factors among American Indian and Alaska native populations. PLoS One. 2014;9(1):e80973. https://doi.org/10.13 71/journal.pone.0080973.

100. Titmuss A, Davis EA, Brown A, Maple-Brown L. Emerging diabetes and metabolic conditions among Aboriginal and Torres Strait Islander young people. Med J Aust. 2019;210(3):111-3.e1.

101. Ramirez-Zea M, Kroker-Lobos MF, Close-Fernandez R, Kanter R. The double burden of malnutrition in indigenous and nonindigenous Guatemalan populations. Am J Clin Nutr. 2014;100:1644s-51s.

102. Wong CY, Zalilah MS, Chua EY, Norhasmah S, Chin YS, Siti Nur'Asyura A. Double-burden of malnutrition among the indigenous peoples (orang Asli) of peninsular Malaysia. BMC Public Health. 2015;15(1):680. https://doi.org/1 0.1186/s12889-015-2058-x.

103. Hudson S. Healthy stores, healthy communities: the impact of outback stores on remote indigenous Australians. St Leonards: Centre for Independent Studies; 2010.

104. Kagie R, Lin S-YN, Hussain MA, Thompson SC. A pragmatic review to assist planning and practice in delivering nutrition education to indigenous youth. Nutrients. 2019;11(3):510. https://doi.org/10.3390/nu11030510,

105. United Nations. Transforming our world: the 2030 Agenda for sustainable development. In: Division for Sustainable Development Goals. New York: United Nations; 2015. https://sustainabledevelopment.un.org/content/ documents/21252030\%20Agenda\%20for\%20Sustainable\%2 ODevelopment\%20web.pdf.

106. Di A. Indigenous health: a worldwide focus. Lancet. 2016:388(10040):104.

107. Rigby RR, Mitchell L, Hamilton K, Williams LT. The use of behavior change theories in dietetics practice in primary health care: a systematic review of randomized controlled trials. J Acad Nutr Diet. 2020;120(7):1172-97. https:// doi.org/10.1016/j.jand.2020.03.019.

108. Gittelsohn J, Rowan M. Preventing diabetes and obesity in American Indian communities: the potential of environmental interventions. Am J Clin Nutr. 2011;93(5):1179S-83S. https://doi.org/10.3945/ajcn.110.003509.

109. Davis PC Jr, Rankin LL. Guidelines for making existing health education programs more culturally appropriate. Am J Health Educ. 2006;37(4):250-2. https://doi.org/10.1080/19325037.2006.10598912.

110. Wali S, Superina S, Mashford-Pringle A, Ross H, Cafazzo JA. What do you mean by engagement? - evaluating the use of community engagement in the design and implementation of chronic disease-based interventions for indigenous populations - scoping review. Int J Equity Health. 2021;20(1):8. https://doi.org/10.1186/s12939-020-01346-6.

111. Cyril S, Smith BJ, Possamai-Inesedy A, Renzaho AMN. Exploring the role of community engagement in improving the health of disadvantaged populations: a systematic review. Glob Health Action. 2015;8(1):29842. https://doi.org/10.3402/gha.v8.29842.

112. Harding T, Oetzel J. Implementation effectiveness of health interventions for indigenous communities: a systematic review. Implement Sci. 2019;14(1):76. https://doi.org/10.1186/s13012-019-0920-4

113. Schembri L, Curran J, Collins L, Pelinovskaia M, Bell H, Richardson C, et al. The effect of nutrition education on nutrition-related health outcomes of Aboriginal and Torres Strait islander people: a systematic review. Aust N Z J Public Health. 2016;40(S1):S42-S7. https://doi.org/10.1111/1753-6405.12392.

\section{Publisher's Note}

Springer Nature remains neutral with regard to jurisdictional claims in published maps and institutional affiliations.

Ready to submit your research? Choose BMC and benefit from:
- fast, convenient online submission
- thorough peer review by experienced researchers in your field
- rapid publication on acceptance
- support for research data, including large and complex data types
- gold Open Access which fosters wider collaboration and increased citations
- maximum visibility for your research: over 100M website views per year
At BMC, research is always in progress.
Learn more biomedcentral.com/submissions

